\title{
The Effect of Eserine upon the Accelerated Adrenaline Secretion Caused by KGl.*
}

By

Tatuzi Suzuki, Susumu Matumoto, Junji Sasaki

(鉿木 澾二) (松 本 進) (佐々木淳二)

and Sannosuke Nunokawa.

(布川三之助)

(From the Physiological Laboratory of Prof. Y. S a take, Tohoku University, Sendai.)

(Received for publication, March 27, 1951)

Having an intimate relation with acetylcholine, potassium ion is considered as an important factor in the synaptic transmission of nerve impulses: It was demonstrated that the potassium ion causes the liberation of acetylcholine when applied to the sympathetic cervical ganglion, ${ }^{11}$ submaxillar gland, tongue, sweat gland ${ }^{21}$ and heart. ${ }^{81}$

Feldberg and Vartiainen ${ }^{4}$ observed that the action of $\mathrm{KGl}$ on the perfused cervical sympathetic ganglion was enhanced to some degree after perfusion with eserine. According to Feldberg and Guimarais, ${ }^{2)}$ the secretory effect of $\mathrm{KCl}$ on the submaxillar gland increases definitely after injection of eserine.

$\mathrm{KCl}$ has an accelerating action upon the adrenaline secretion, which was demonstrated on non-anesthetized dogs in our laboratory by Arai et al.5) To know whether the adrenaline secreting action of $\mathrm{KCl}$ is likewise enhanced by eserine or not, the present. studies were undertaken. Some authers reported the papers dealing with similar question, but we had found non-agreement in their experimental results.

$\mathrm{Katz}$ and $\mathrm{Katz}^{6}$ ) experimented on with dial anesthetized, eviscerated cats with restricted circulation, using the rise of blood pressure and a retraction of the denervated nictitating membrane as an indicator of an augmented adrenaline secretion. $\mathrm{KCl}$ was injected into the central end of the coeliac artery before and after intravenous injection of eserine. Their experimental results were not constant. In some cases the augmented adrenaline secretion caused by $\mathrm{KCl}$ was not enhanced after eserine. However in some experiments eserine enhanced the action of $\mathrm{KGl}$ definitely.

* Reported at the XX Annual Meeting of the Japanese Physiological Society at Taihoku, July 1941. (Nihon Seiri Z., 1941, 6, 141; Jap. J. Med. Sci., Biophysics, 1943, 8, 16.*) 
In the same year, Kohler and Lévy") reported the accelerating action of $\mathrm{KCl}$ upon the adrenaline secretion seemed to be not enhanced with eserine.

On the other hand, Hermann et al. ${ }^{8)}$ noticed a remarkable increase of the adreno-secretory action of $\mathrm{KCl}$ after eserine injection. Using the method of the suprareno-jugular anastmosis, $\mathrm{KCl}$ was injected intravenously into the donor dog with the acutely or chronically denervated suprarenals before or after eserine injection. The elevation of blood pressure of a recipient dog caused by $\mathrm{KCl}$ after eserine was definitly intensiver than that before eserine.

In our experiments the effect of eserine upon the adrenaline secretory action of $\mathrm{KCl}$ was studied quantitatively on non-anesthetized dogs.

\section{Method.}

In dogs the $\mathrm{D}_{11}-\mathrm{L}_{3}$ dorsal spinal roots were cut under morphineether-narcosis, and about 4-11 weeks later the experiments were carried out. The suprarenal vein blood was sampled by using the lumbar route method of Satake et al. ${ }^{9}$ ) without anesthesia, and the adrenaline in the suprarenal vein blood was estimated by means of the rabbit intestine segment method. The blood pressure was registered by a mercury manometer from the femoral artery. A small cannula for injection was inserted in the saphena vein.

$\mathrm{KGl}$ was injected in a dose of $30-38 \mathrm{mg}$ per $\mathrm{kg}$ of body weight as a $3-10 \%$ solution intravenously in about 15 seconds. Just after the start of $\mathrm{KCl}$-injection the sampling of suprarenal vein blood was started. The same dose of $\mathrm{KCl}$ was injected again 0.5-1 hour after the first $\mathrm{KCl}$ injection and some minutes before the second $\mathrm{KCl}$-injection eserine was injection. Eserine salicyl. (Merk) was as a $0.05 \%$ solution in a dose of $0.3 \mathrm{mg}$ per $\mathrm{kg}$ in 60 seconds intravenously injected. As a control experiment, eserine was not used in Exp. 1. Only $\mathrm{KCl}$ in the same dose was injected intravenously twice with the interval of half an hour.

\section{Results.}

To show the outline of the experimental procedures, an example (Exp. 5) is given in full in Tab. I. with the protocol the blood pressure tracings are produced in Fig. 1.

\section{Exp. 1 (Control experiment) A male dog, $18.5 \mathrm{~kg}$ (9. V. 1941)}

In this dog, $\mathrm{KGl}$ was injected intravenously in a dose of $33 \mathrm{mg}$ per $\mathrm{kg}$ in 15 seconds. The animal excited slightly. The blood pressure fell transitorily from $87 \mathrm{~mm} \mathrm{Hg}$ to $74 \mathrm{~mm} \mathrm{Hg}$ within 13 seconds after the start of injection" 
but soon it returned to the initial height. Some seconds later, the blood pressure began to fall promptly and 6 seconds later its lowest height of $47 \mathrm{~mm}$ Hg was reached. The rate of heart beat decreased. Then the blood pressure rose and resumed its initial height within 43 seconds after the start of injection.

The adrenaline secretion rate, which was $0.02-0.03 \gamma$ per $\mathrm{kg}$ per minute from one gland before injection, increased after $\mathrm{KCl}$ injection to $0.35 \%$ per $\mathrm{kg}$ per minute in the first thirty-second-period. In the second thirty-secondperiod, the secretion rate was somewhat larger than the initial rate but in the third thirty-second-period it was almost the initial value.

About half an hour, $33 \mathrm{mg} \mathrm{KCl}$ per $\mathrm{kg}$ of body weight was again injected intravenously in 15 seconds. The dog excited slightly. The blood pressure fell temporarily (during about 4 seconds) within 12 seconds after the start of injection. Some seconds later, the blood pressure began to fall from $94 \mathrm{~mm}$ $\mathrm{Hg}$, and 4 seconds later it reached $53 \mathrm{~mm} \mathrm{Hg}$. The slowing of the heart beat occurred. Then the blood pressure turned to rise and recovered its initial height 31 seconds after the start of injection.

The adrenaline secretion rate before the second $\mathrm{KGl}$ injection was $0.02 \gamma$ per $\mathrm{kg}$ per minute. On the injection, it increased to $0.38 \mathrm{r}$ per $\mathrm{kg}$ per minute in the first thirty-second-period. In the second thirty-second-period, it resumed almost the pre-injection rate.

In this control experiment we ascertained that $\mathrm{KCl}$ in the same dose evoked the acceleration of adrenaline secretion of almost the same intensity.

Exp. 2 A male dog, $11.0 \mathrm{~kg}$ (19. IX. 1940)

$\mathrm{KCl}$ was injected intravenously in a dose of $30 \mathrm{mg}$ per $\mathrm{kg}$ in 17 seconds. Excitement was not observed, but the pupils dilated. Within 9 seconds after the start of injection, the blood pressure fell temporarily from $95 \mathrm{~mm} \mathrm{Hg}$ to $.72 \mathrm{~mm} \mathrm{Hg}$ and soon it returned to the initial height. The adrenaline secretion rate, which was $0.03 \mathrm{r}$ per $\mathrm{kg}$ per minute before the $\mathrm{KGl}$ injection increased to $0.39 \gamma$. But soon the adrenaline secretion rate resumed almost the preinjection value.

About an hour after the first $\mathrm{KCl}$ injection, $0.3 \mathrm{mg}$ per $\mathrm{kg}$ of eserine was injected intravenously in 60 seconds. The pupils dilated. After the end of injection, the blood pressure rose gradually. The adrenaline secretion rate was $0.03-0.04 \gamma$ per $\mathrm{kg}$ per minute, within 4 minutes after eserine injection. 6 minutes later, the animal salivated and urinated.

11 minutes after eserine, $30 \mathrm{mg} \mathrm{KCl}$ per $\mathrm{kg}$ was again injected intravenously in 18 seconds. The blood pressure did not fall, but rose gradually after the end of injection. The adrenaline secretion rate was measured as $1.1 \mathrm{r}$ per $\mathrm{kg}$ per minute in the first thirty-second-period. With the next specimen, the secretion rate was measured as a double of the initial value, but thereafter it resumed nearly the rate of pre-injection.

Exp. 3 A female dog, $13.3 \mathrm{~kg}(8$. X. 1940) 
$\mathrm{KCl}$ was injected intravenously in a dose of $33 \mathrm{mg}$ per $\mathrm{kg}$ of body weight in 15 seconds. The dog did not excite. Within 17 seconds after the start of injection, the blood pressure rose from $87 \mathrm{~mm} \mathrm{Hg}$ to $98 \mathrm{~mm} \mathrm{Hg}$, but soon it began to fall and 9 seconds later its lowest height $(55 \mathrm{~mm} \mathrm{Hg})$ was reached. The slowing of the heart beat occurred. Then the blood pressure. rose up to $77 \mathrm{~mm} \mathrm{Hg}$ within 36 seconds after the start of injection. The initial rate of adrenaline secretion of this dog was $0.02-0.03 \gamma$ per $\mathrm{kg}$ per min. On the injection, the secretion rate increased to $0.22 \gamma$ per $\mathrm{kg}$ per minute during the first thirty-second-period. With the specimen, which was collected in the second thirty-second-period, the rate of adrenaline secretion was about double as much as that of initial value but in the third thirtysecond-period it resumed almost the pre-injection value.

About half an hour later, eserine was injected intravenously in a dose of $0.3 \mathrm{mg}$ per $\mathrm{kg}$ of body weight in 60 seconds. Soon after eserine pupils dilated and the respiratory movements became deep and rough. Shivering was observed. The blood pressure rose gradually. The rate of the heart beat rather decreased. 5 minutes after eserine injection, the adrenaline secretion rate was $0.03 \gamma$ per $\mathrm{kg}$ per $\min$.

8 minutes after eserine injection, $33 \mathrm{mg}$ per $\mathrm{kg} \mathrm{KCl}$ was again injected intravenously in 16 seconds. The animal urinated and defectaed. The blood pressure rose gradually from $118 \mathrm{~mm} \mathrm{Hg}$ and reached $142 \mathrm{~mm} \mathrm{Hg}$ within 23 seconds after the start of injection. The adrenaline secretion rate increased definitely after the injection. In the first thirty-second-period, it was $1.7 \gamma$ per $\mathrm{kg}$ per min., and in the next thirty-second-period the secretion rate was $0.17 \mathrm{r}$ per $\mathrm{kg}$ per minute. With the specimen taken in the third thirty-secondperiod, it was still over the pre-injection value.

\section{Exp. 4 A male dog, $19.2 \mathrm{~kg}$ (26. XI. 1940)}

In this dog, $\mathrm{KCl}$ was injected intravenously in a dose of $38 \mathrm{mg}$ per $\mathrm{kg}$ in. 17 seconds. Within 13 seconds after the start of injection the blood pressure rose from $88 \mathrm{~mm} \mathrm{Hg}$ to $98 \mathrm{~mm} \mathrm{Hg}$, but soon it began to fall and reached 56 $\mathrm{mm} \mathrm{Hg}$ within 25 seconds after the start of injection. The rate of heart beat decreased. Then the blood pressure turned to rise and elevated to $92 \mathrm{~mm} \mathrm{Hg}$. The basal secretion rate of adrenaline was $0.03 \mathrm{r}$ per $\mathrm{kg}$ per min. On the $\mathrm{KCl}$ injection, the adrenaline secretion rate was found to have increased in the first thirty-second-period to $0.26 \mathrm{r}$ per $\mathrm{kg}$ per min. In the second thirtysecond-period it was still somewhat larger than the initial value.

About half: an hour after the first $\mathrm{KCl}$ injection, $0.3 \mathrm{mg}$ per $\mathrm{kg}$ of eserine was injected in 60 seconds. The pupils dilated. The blood pressure rose from $88 \mathrm{~mm} \mathrm{Hg}$ gradually after the end of injection. 2 minutes later 175 $\mathrm{mm} \mathrm{Hg}$ was reached. The secretion rate of adrenaline was $0.04 \mathrm{r}$ per $\mathrm{kg}$ per minute. Then $38 \mathrm{mg}$ per $\mathrm{kg}$ of $\mathrm{KCl}$ was again injected intravenously in 17 seconds. The blood pressure began to fall from $180 \mathrm{~mm} \mathrm{Hg}$ within 20 seconds after the start of injection and 5 seconds later it reached $124 \mathrm{~mm} \mathrm{Hg}$. The rate of heart beat decreased. Then the pressure began to rise and reached 
$176 \mathrm{~mm} \mathrm{Hg}$. The adrenaline secretion rate in the first thirty-second-period was $0.7 \gamma$ per $\mathrm{kg}$ per min. In the second thirty-second-period the secretion rate resumed nearly its pre-injection value.

\section{Exp. 5 A female dog, $15.4 \mathrm{~kg}$ (3. XII. 1940)}

The basal adrenaline secretion rate in this dog was $0.02 \gamma$ per $\mathrm{kg}$ per -minute. KCl was injected intravenously in a dose of $35 \mathrm{mg}$ per $\mathrm{kg}$ in 15
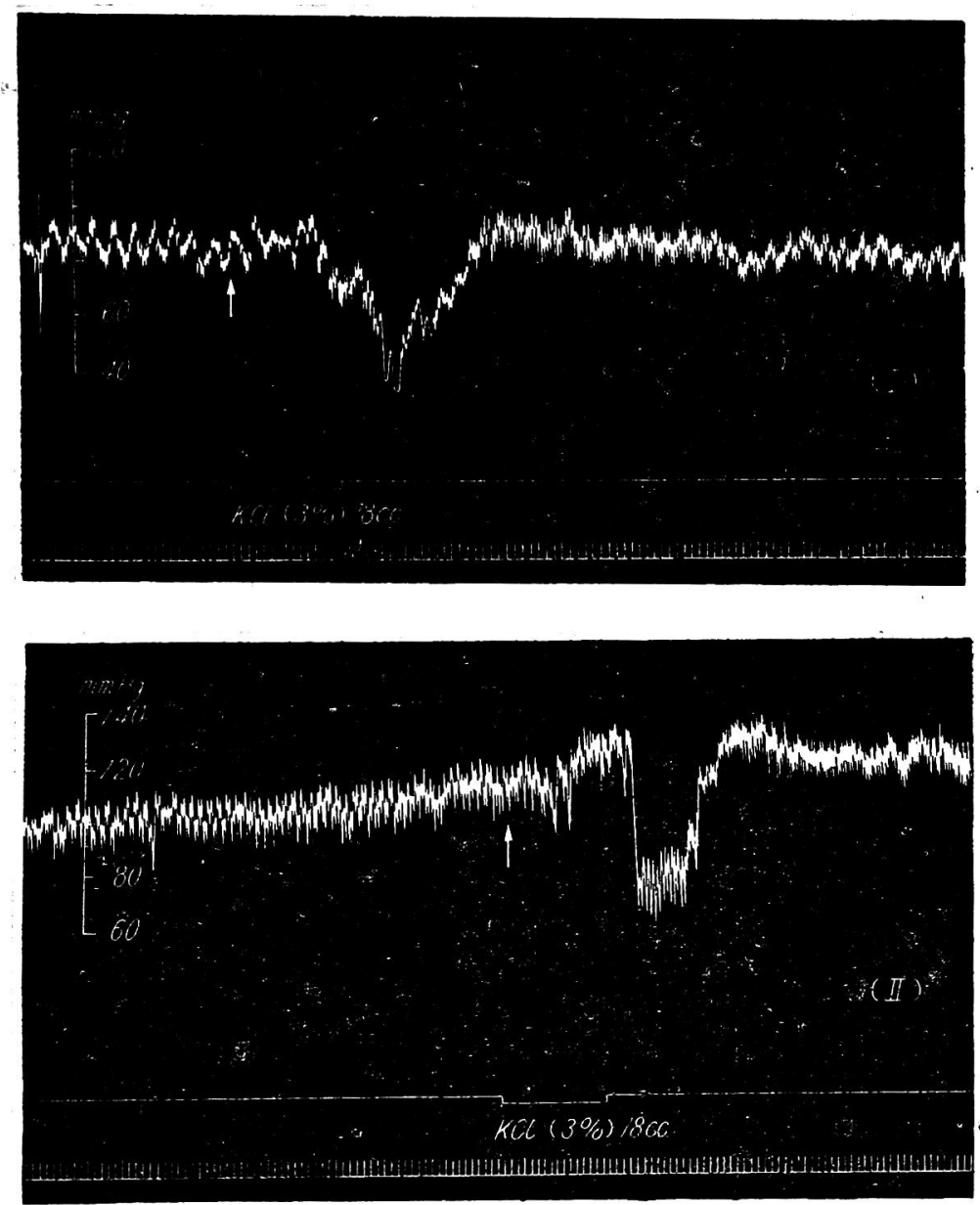

Fig. 1. Blood pressure tracings in Exp. 5. (Reduced to 3/5): Dog $15.4 \mathrm{~kg}$ 우, nonanesthetized.

KCI was injected intravenously in a dose of $35 \mathrm{mg}$ per $\mathrm{kg}$ of body weight.

(I) $\mathbf{K C l}$ injection before eserine.

(II) $\mathrm{KCl}$ injection after eserine.

Time in seconds. 
TABLE I.

Exp. 5. 3. XII. 1940 Dog \& $15.4 \mathrm{~kg}$

\begin{tabular}{|c|c|c|c|c|c|c|c|c|c|}
\hline$\underset{g}{\mathscr{g}}$ & 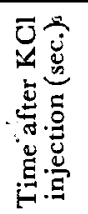 & 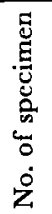 & 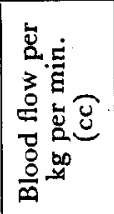 & 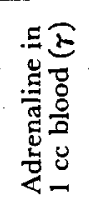 & 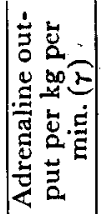 & 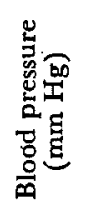 & 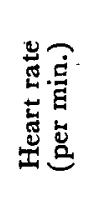 & 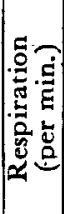 & 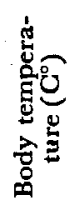 \\
\hline
\end{tabular}

31. X. $194015.3 \mathrm{~kg} \quad \mathrm{D}_{11}-\mathrm{L}_{3}$ dorsal spinal roots severed.

9:50 a.m.-11:40 a.m. The left lumbar route preparation.

The left femoral artery and the right saphena vein prepared.

\begin{tabular}{|c|c|c|c|c|c|c|c|c|}
\hline $\begin{array}{l}1: 36 \text { p.m. } \\
1: 45\end{array}$ & $\begin{array}{l}1 \\
2\end{array}$ & $\begin{array}{l}0.49 \\
0.41\end{array}$ & $\begin{array}{l}0.05 \\
0.05\end{array}$ & $\begin{array}{l}0.02 \\
0.02\end{array}$ & 86 & 150 & 30 & 39.0 \\
\hline $\begin{array}{l}48 \\
50\end{array}$ & 3 & 0.35 & 0.05 & 0.02 & 82 & 135 & 24 & \\
\hline & 4 & 0.43 & 0.05 & 0.02 & 85 & 159 & 23 & \\
\hline
\end{tabular}

2:11 Injected intravenously $9.2 \mathrm{cc}$ of $0.05 \% \mathrm{KCl}$ (35 $\mathrm{mg}$ per $\mathrm{kg}$ ) in 15 seconds.

\begin{tabular}{l|c|c|c|c|c|c|c|c|c} 
& $0-30$ & 5 & 0.57 & 1.0 & 0.57 & $85-39-66$ & $168-60-168$ & & \\
$2: 22$ & $30-60$ & 6 & 0.53 & 0.05 & 0.03 & $66-35$ & 168 & 30 \\
$2: 32$ & $60-90$ & 7 & 0.56 & 0.05 & 0.03 & 85 & 168 & 26 & \\
& & 8 & 0.41 & 0.05 & 0.02 & 71 & 162 & 30 & 38.8 \\
& & 9 & 0.39 & & & & & &
\end{tabular}

2:33 Injected intravenously $9.2 \mathrm{cc}$ of $0.05 \%$ eserine ( $0.3 \mathrm{mg}$ per $\mathrm{kg}$ ) in 60 seconds.

$2: 33$

$2: 36$

$2: 37$

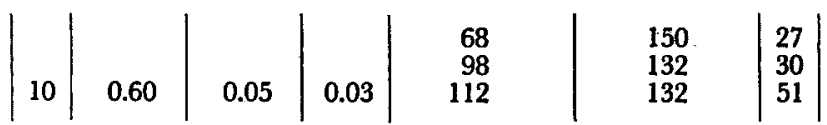

Injected intravenously $18 \mathrm{cc}$ of $3 \% \mathrm{KCl}$ ( $35 \mathrm{mg}$ per $\mathrm{kg}$ ) in 16 seconds.

\begin{tabular}{l|c|c|c|c|c|c|c|c|c} 
& $0-30$ & 11 & 0.95 & 2.0 & 1.9 & $126-74-94$ & $168-96-110$ & & \\
& $30-60$ & 12 & 0.79 & 0.2 & 0.16 & $94-128-121$ & $110-171$ & 11 & \\
$2: 45$ & $60-90$ & 13 & 0.60 & 0.05 & 0.03 & 125 & 153 & 11 & \\
$2: 47$ & & 14 & 0.51 & 0.05 & 0.03 & 112 & 168 & 30 & 39.0 \\
$2: 55$ & & 15 & 0.49 & & & 111 & 171 & 52 & \\
$3: 04$ & & & & & & 104 & 177 & 48 & 39.1 \\
$3: 09$ & & 16 & 0.41 & 0.05 & 0.02 & 98 & 153 & 42 & \\
$3: 11$ & & 17 & 0.43 & & & & 162 & 45 & \\
& & & & & & & & & 39.2
\end{tabular}

Room temperature $17-18^{\circ} \mathrm{C}$.

seconds. During the injection the animal barked. The blood pressure began to fall from $85 \mathrm{~mm} \mathrm{Hg}$ within 12 seconds after the start of injection and 11 seconds later its lowest level $(39 \mathrm{~mm} \mathrm{Hg})$ was reached. The rate of the heart beat decreased markedly. Then the blood pressure rose and 13 seconds later it returned almost to the initial height. The rate of adrenaline secretion measured 
with the specimen taken in the first thirty-second-period was $0.57 \gamma$ per $\mathrm{kg}$ per minute. In the second thirty-second-period, the rate of secretion resumed the initial value.

About twenty. minutes after the $\mathrm{KGl}$ injection, eserine was injected intravenously in a dose of $0.3 \mathrm{mg}$ per $\mathrm{kg}$ in 60 seconds. After finishing the eserine injection, the pupils dilated and the respiration became rough and deep. The blood pressure rose from $68 \mathrm{~mm} \mathrm{Hg}$ gradually. Two minutes later, the animal struggled. The adrenaline secretion rate was $0.03 \gamma$ per $\mathrm{kg}$ per min.

$35 \mathrm{mg}$ per $\mathrm{kg}$ of $\mathrm{KGl}$ was again injected intravenously in 16 seconds. The animal shivered. The blood pressure fell promptly from $126 \mathrm{~mm} \mathrm{Hg}$ to $74 \mathrm{~mm} \mathrm{Hg}$ within 20 seconds after the start of injection and lasted for 8 seconds. Slowing of the heart beat occurred. Then the blood pressure rose and returned to initial height 33 seconds after the start of injection.

The adrenaline secretion rate accelerated markedly after injection. It was $1.9 \mathrm{r}$ per $\mathrm{kg}$ per minute in the first thirty-second-period. In the second thirty-second-period, the rate of adrenaline secretion was $0.16 \gamma$ per $\mathrm{kg}$ per min. In the third thirty-second-period the secretion rate of adrenaline resumed the pre-injection value.

From the description quoted above, it is known that the accelerating action of $\mathrm{KCl}$ upon the adrenaline secretion of the suprarenals is enhanced by eserine.

\section{Summary.}

In dogs, the suprarenal vein blood was collected without narcotizing. Adrenaline in the blood specimen was determined by means of the rabbit intestine segment method.

At first, 30-38 mg per $\mathrm{kg}$ of $\mathrm{KGl}$ was injected intravenously in 15 seconds. After about half an hour, $0.3 \mathrm{mg}$ per $\mathrm{kg}$ eserine was injected intravenously in 60 seconds, and 4-11 minutes later $\mathrm{KCl}$ in a same dose was again injected. The adrenaline secretion after the second $\mathrm{KCl}$ injection was compared with that of the first $\mathrm{KCl}$ injection.

Before injection, the rate of adrenaline secretion from one gland was 0.02-0.03 $\gamma$ per $\mathrm{kg}$ per min. At the first $\mathrm{KCl}$ injection, it increased to $0.22-0.57 \gamma$ per $\mathrm{kg}$ per min. After eserine, and before the second $\mathrm{KCl}$ injection, the rate of adrenaline secretion was $0.03-0.04 \gamma$ per $\mathrm{kg}$ per min. At the second $\mathrm{KCl}$ injection, it increased to $0.7-1.9 \gamma$ per $\mathrm{kg}$ per min.

Thus it is clear that the accelerating action of $\mathrm{KCl}$ upon the adrenaline secretion is enhanced by eserine.

\section{References.}

1 Brown and Feldberg, J. Physiol., 1935, 84, 12 P; 1936, 86, 297 ff.

2 Feldberg and Guimarais, ibid., 1936, 86, 306.

3 Beznak, ibid., 1934, 82, $147 \mathrm{f}$. 
4 Feldberg and Vartiainen, ibid., 1935, 83, $124 \mathrm{ff}$.

5. Arai, Outi and Wada, Nihon Seiri. Z., 1940, 5, 133; Jap. J. Med. Sci., Biophysics 1941, 7, 69:*

6 Katz and Katz, Proc. Soc. Exp. Biol. \& Med., 1937, 36, 848.

7 Kohler and Levy, C. R. Soc. Biol., 1937, 126, 405.

8 Hermann, Jourdan, Morin and Vial, ibid., 1938, 127, 613; 1938, 128, 676.

9 Satake, Sugawara and Watanabe, Tohoku J. Exp. Med., 1927, 8, 501. 